\title{
Characteristics of Graves' Disease in a Cohort of Chronic Hepatitis C Patients Treated With Interferon- $\alpha$ and Ribavirin
}

\author{
Huy A Tran ${ }^{\mathrm{a}, \mathrm{b}}$, Glenn EM Reeves ${ }^{\mathrm{a}}$
}

\begin{abstract}
Background: Thyrotoxicosis resembling Graves' disease (GD) in association with interferon- $\alpha$ therapy in the treatment of chronic hepatitis $\mathrm{C}$ is very uncommon, especially after treatment has ceased. Furthermore, it is unknown if this condition behaves differently from GD arising de novo.
\end{abstract}

Methods: A retrospective analysis was performed to detect and review all cases of GD occurring in our hepatitis $\mathrm{C}$ service unit over a five year period including long term outcomes.

Results: There were five cases of GD detected: 3 females and 2 males. These were: 1 case of co-existing GD and a toxic nodule developed during therapy, 2 cases developed GD after therapy and another 2 as part of the tri-phasic thyroiditis. All 5 patients were treated for 6 months with one exception and then followed up for another 12 months.

Conclusions: All patients responded satisfactorily to short term thionamides and remained in long term remission. Although the number is small, this report is a reminder that more cases can be expected as treatment for chronic $\mathrm{HCV}$ is likely to increase.

Keywords: Graves' disease; Chronic; Hepatitis C; Therapy; Interferon- $\alpha$; Ribavirin; Thionamide

Manuscript accepted for publication April 12, 2011

${ }^{a}$ Hunter Area Pathology Service, John Hunter Hospital, Locked Bag Number 1, Hunter Mail Region Center, Newcastle, New South Wales 2310, Australia

${ }^{\mathrm{b}}$ Corresponding author: Huy A Tran, Department of Clinical Chemistry, Hunter Area Pathology Service, John Hunter Hospital, Newcastle,

New South Wales 2310, Australia.

Email: huy.tran@hnehealth.nsw.gov.au

doi:10.4021/jem $10 \mathrm{w}$

\section{Introduction}

Spontaneous Graves' disease (GD) is not an uncommon condition in the general community with a prevalence of about 0.5 to $1.0 \%$ [1, 2]. Another form of GD has also been observed and described in association with interferon- $\alpha$ $(\mathrm{IFN}-\alpha)$ therapy, either alone or as part of combination therapy for chronic hepatitis $\mathrm{C}$ infection [3]. The characteristics of this particular condition are poorly defined, primarily due to its low prevalence, compounded by a lack of awareness of its occurrence. Because of this deficiency, treatment is often ad hoc, occasionally with radioactive iodine which can render patients unnecessarily permanently hypothyroid. This report seeks to find out the prevalence of this condition, its response to conventional medical therapy and medium term follow-up as well as a review of the current literature.

\section{Methods}

\section{Patients}

The Hunter Area Hepatitis C treatment center assesses and treats referred cases of hepatitis C in Northern New South Wales, Australia. It is part of the John Hunter Hospital, a major tertiary referral center in the state. A total of 516 patients ( 282 males and 234 females) were treated between 1/1/2005 and 31/12/2009, a period of 60 months. All cases of GD were reviewed in patients with chronic hepatitis $\mathrm{C}$ who had undergone combination IFN- $\alpha$ and ribavirin (RBV) therapy. All were also reviewed and managed in consultation with a dedicated endocrinology team for the service.

\section{Definition}

Graves' disease was defined as clinical and biochemical thyrotoxicosis, elevated human thyrotropin receptor antibody (hTRAB) titres and/or increased radioisotope nuclear uptake scans. The parameters for thyrotoxicosis were thyrotropin (TSH) of $<0.1 \mathrm{mU} / \mathrm{L}$, either free tetra-iodothyronine (fT4) levels $>20.6$ and/or free tri-iodothyronine (fT3) levels $>6.0$ 
$\mathrm{pmol} / \mathrm{L}$ respectively.

\section{Laboratory assay characteristics}

Third generation TSH and serum fT4 levels were determined by two-site sandwich immunoassay using an automated chemiluminescent system (Diagnostic Products Corporation, Immulite 2000). The reference range (RR) for TSH was 0.4 - $4.0 \mathrm{mU} / \mathrm{L}$ and fT4 $10.5-20.6 \mathrm{pmol} / \mathrm{L}$. The coefficients of variation $(\mathrm{CV})$ were $5.0 \%$ and $5.1 \%$ at $\mathrm{TSH}$ concentrations of $4.0 \mathrm{mU} / \mathrm{L}$ and $10.0 \mathrm{mU} / \mathrm{L}$ respectively. For $\mathrm{fT} 4$, the $\mathrm{CV}$ was $6.5 \%$ at $10.0 \mathrm{pmol} / \mathrm{L}$.

Similarly, fT3 levels were performed using a two-site sandwich immunoassay using an automated chemiluminescent system (Beckman Coulter DXI). The RR was 3.5 - 6.0 $\mathrm{pmol} / \mathrm{L}$ with $8.7 \% \mathrm{CV}$ at $6.0 \mathrm{pmol} / \mathrm{L}$.

Human TRAb assay was measured with the TRAK LUMI test (B.R.A.H.M.S.AG, Hennigsdorf/Berlin, Germany). An hTRAb level of $<1.0 \mathrm{IU} / \mathrm{L}$ is considered negative and $>2.0$ as conclusively positive.

Serum autoantibodies to thyroglobulin and thyroperoxidase were measured by ELISA method (Aesku Diagnostics, Germany) with reference ranges being $<150 \mathrm{IU} / \mathrm{mL}$ and $<$ $50 \mathrm{IU} / \mathrm{mL}$ respectively.

\section{Thyroid nuclear uptake scans}

These were performed using 99m-pertechnetate tracer with uptake studies taken at about 20 minutes post injection with a normal uptake ratio of $3-8: 1$.

\section{Results}

Five cases of GD were detected, either as the primary diagnosis or part of the tri-phasic thyroiditis as previously reported [4]. This constituted a prevalence of about $1 \%$.

All patients consented to be part of this study. Because of the small number, each individual case is presented in detail below.

\section{Clinical case notes}

\section{Case 1}

A 53-year-old woman with chronic hepatitis C (genotype 3) presented with acute thyrotoxic symptoms. Her past medical history included intravenous drug use which led to the acquisition of hepatitis $\mathrm{C}$ about 20 years prior. She had been treated with combination IFN- $\alpha$ and RBV till the 16 th week when she developed palpitation, anxiety, dyspnoea and recurrent diarrhoea. There was no prior or family of thyroid disease. She did not smoke nor drink and denied any eye or skin symptoms. Clinically she was unwell, anxious and lethargic with blood pressure of 130/60, pulse rate was regular at 108 beats per minute. Her weight was $58.3 \mathrm{~kg}$, height of $1.65 \mathrm{~m}$, body mass index (BMI) $21 \mathrm{~kg} / \mathrm{m}^{2}$. There was a diffuse non-tender goitre. There was no bruit or peripheral stigmata of thyrotoxicosis. Her TSH was $<0.03 \mathrm{IU} / \mathrm{L}$, fT4 102.5 , and fT3 of $39.7 \mathrm{pmol} / \mathrm{L}$. Her hTRAb was elevated at $30.2 \mathrm{IU} / \mathrm{L}(<2)$, anti-thyroperoxidase antibody (anti-TPO) $271(<50)$, anti-thyroglobulin antibody (anti-Tg) $10(<150)$. Her thyroid uptake scan showed an intense uptake in the right lobe, consistent with a hyperfunctioning nodule, and patchy uptake in the rest of the gland. The average overall uptake ratio was $6 \%$. A diagnosis of interferon-induced GD was made with a co-existing toxic solitary nodule, not previously described in this setting.

Because of her anxiety and unstable psychological state, interferon therapy was terminated at this time, the 16 th week of therapy. Carbimazole was started and the patient recovered slowly. She became hypothyroid on minimal carbimazole at 6 months and hence this was terminated with regular thyroid function surveillance. At a further 12 months after cessation, the patient remained euthyroid.

\section{Case 2}

A 47-year-old Caucasian man with chronic hepatitis $\mathrm{C}$ of genotype 1 presented with T3-toxicosis. He had been treated with combination IFN- $\alpha$ and RBV for 48 weeks. He tolerated treatment well until 6 weeks after completion when he developed general lethargy and mild intermittent palpitation. There were no other thyrotoxic symptoms, previous or family history thereof of thyroid disease. All his serial TSH levels during therapy had been normal.

Clinically, he appeared tired with weight of $67.2 \mathrm{~kg}$ and height of $1.75 \mathrm{~m}$ (BMI $\left.22 \mathrm{~kg} / \mathrm{m}^{2}\right)$. His cardiovascular examination was satisfactory with regular pulse rate of 88 beats per minute, blood pressure $130 / 80$. There was no goitre or peripheral stigmata of thyrotoxicosis, including exophthalmopathy or dermatopathy. His TSH was $<0.03$, with fT4 of 17.5 and fT3 of $8.2 \mathrm{pmol} / \mathrm{L}$. His hTRAb was $16.6 \mathrm{IU} / \mathrm{L}$, anti-Tg and anti-TPO were 188 and 26 respectively. His thyroid technetium uptake was elevated at 9\%. He was assessed to have GD in association with IFN- $\alpha$ therapy. Carbimazole was initiated and remission was achieved after 8 weeks. Therapy was discontinued after 6 months at the patient's insistence. He was subsequently followed up at 12 months when he remained euthyroid.

\section{Case 3}

A 43-year-old woman with a history of breast cancer, chronic hepatitis $\mathrm{C}$ complicated by porphyria cutanae tarda presented with acute thyrotoxic symptoms. Her breast cancer was successfully treated 10 years prior and was deemed in remission with annual assessment. She carried the genotype 1 and thus 


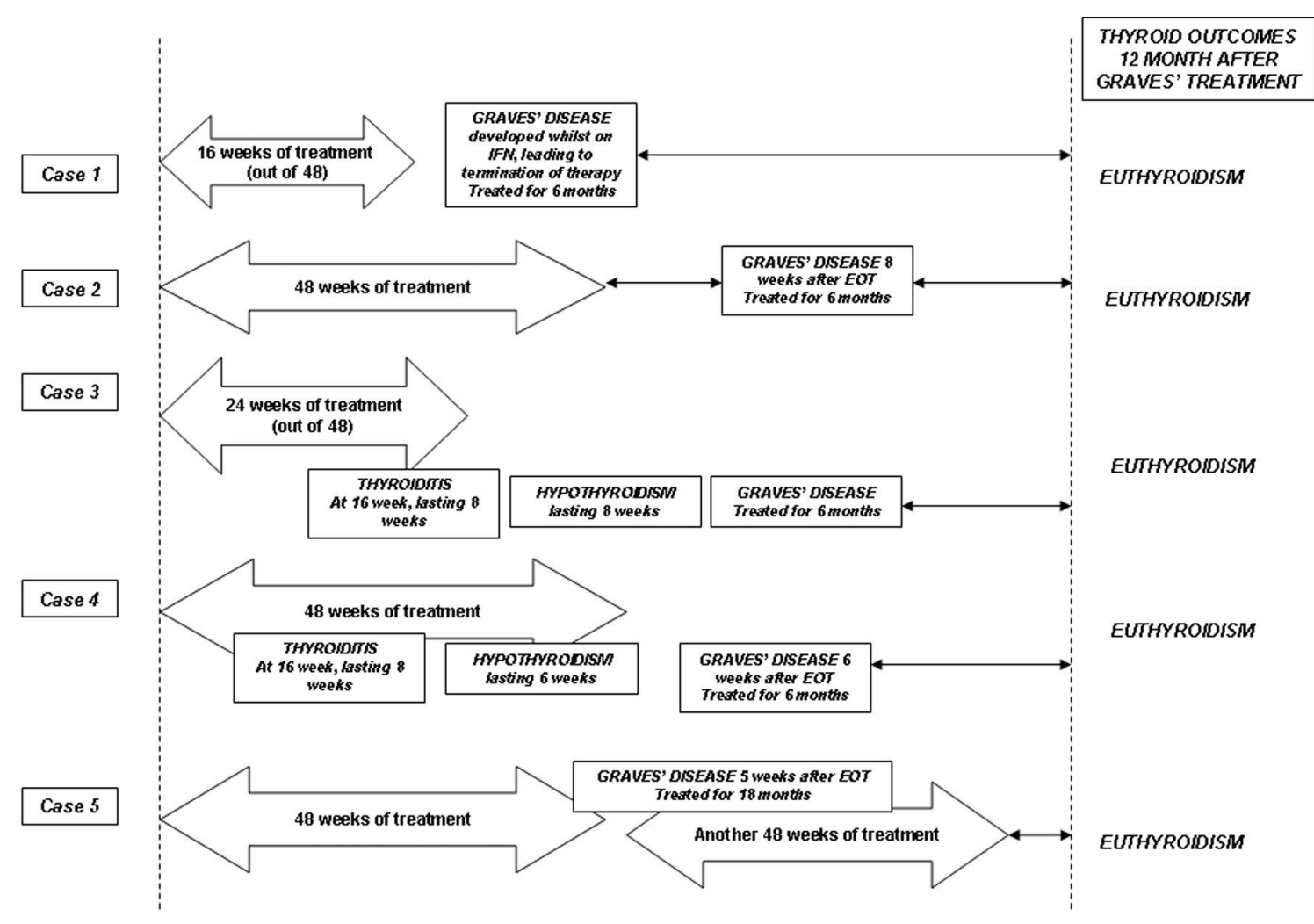

Figure 1. Schematic summaries of the cases and their final thyroid outcomes. The arrow bars indicate the duration of combination therapy with interferon- $\alpha$ and ribavirin. See text for detailed discussions.

was due to be treated for 42 weeks with RBV and IFN- $\alpha$. She developed thyrotoxic symptoms at 16 weeks with diarrhoea and palpitation with weight loss. Clinical examination found her to be tired and lethargic with pulse of 98 regular and BP of 140/85. There was no goitre and no other evidence of GD. Her TSH was $<0.03$, fT4 78.0 and fT3 6.9 pmol/L. Her anti$\mathrm{Tg}$ and anti-TPO were elevated at 1597 and 1176 respectively. Her hTRAB was 3.3. Her thyroid scan was consistent with thyroiditis with a 20 -minute uptake of $1 \%$. She was treated with beta-blocker with good symptom relief. Hypothyroidism then developed with constipation and pedal edema. As a result, she was given a temporary thyroxine supplement. At week 24, she did not achieve early virological response and hence treatment was terminated. However, she began to feel again unwell at week 32 with tremors and general anxiety. She was found to be biochemically toxic with $\mathrm{TSH}<0.03$, fT4 of 28.9 and fT3 $8.9 \mathrm{pmol} / \mathrm{L}$. This time, her hTRAB was elevated at 5.4 with normalization of her anti-Tg and antiTPO. Her repeat thyroid uptake scan showed an $8 \%$ uptake. This was confirmed to be GD, similar to case 4 . The patient responded rapidly to carbimazole. She too was sensitive to this medication necessitating stopping at 6 months. After a further 12 month follow-up, she remained euthyroid.

\section{Case 4}

A 53-year-old Caucasian man presented with acute thyroiditis whilst undergoing combination RBV and IFN- $\alpha$ therapy for his hepatitis $\mathrm{C}$ infection. Because of his HCV genotype 1 , treatment duration was to be 48 weeks. He had no medical history of note, smoked 5 - 10 cigarettes daily and has been tolerating the treatment regimen well. He developed IFNinduced thyroiditis at the 28th week of therapy and had recovered completely by the end of therapy. The patient completed treatment uneventfully at 48 weeks at which time his TSH, fT4 and fT3 levels had returned to normal. At 8 weeks post treatment, he complained of non-specific lethargy and a $2.5 \mathrm{~kg}$ weight loss. Repeat thyroid function tests showed T3-thyrotoxicosis with again, suppressed TSH, fT4 of 21.1 and fT3 $8.0 \mathrm{pmol} / \mathrm{L}$. His anti-Tg was 64, anti-TPO 228 and hTRAb was $19.3 \mathrm{U} / \mathrm{mL}$. A pertechnetate uptake scan showed diffuse and increased uptake at $12 \%$, consistent with GD. At 12 weeks post IFN therapy, his T3-toxicosis persisted with fT3 level of $8.7 \mathrm{pmol} / \mathrm{L}$ and propylthiouracil (PTU) was initiated. He was rendered euthyroid 6 weeks later. PTU was continued for another 6 months. His liver function tests remained stable throughout the duration. He self-terminated 
Table 1. Characteristics and Long Term Follow-up of 5 Patients Who Developed Graves' Disease in Conjunction With Interferon- $\alpha$ and Ribavirin Therapy

\begin{tabular}{|c|c|c|c|c|c|c|c|}
\hline $\begin{array}{l}\text { Subject } \\
\text { No. }\end{array}$ & Gender/Age & Ethnicity & Duration & Thyroid Scan & Final Diagnosis & Treatment & $\begin{array}{l}\text { Long Term } \\
\text { Outcome } \\
\text { (12 months after } \\
\text { end of treatment) }\end{array}$ \\
\hline 1 & $\mathrm{~F} / 53$ & $\mathrm{C}$ & 16 & $\begin{array}{l}\text { Toxic nodule \& } \\
\text { diffuse uptake } 6 \%\end{array}$ & $\begin{array}{l}\text { Mixed Graves' } \\
\text { disease and toxic } \\
\text { solitary nodule }\end{array}$ & CBZ for 6 months & Euthyroidism \\
\hline 2 & $\mathrm{M} / 47$ & $\mathrm{C}$ & 48 & $8 \%$ diffuse uptake & Graves' disease & CBZ for 6 months & Euthyroidism \\
\hline \multirow[t]{2}{*}{3} & \multicolumn{3}{|c|}{ Phase 1 (thyroiditis phase) } & Negligible uptake & $\begin{array}{l}\text { Triphasic thyroiditis, } \\
\text { Graves' disease }\end{array}$ & $\begin{array}{l}\text { Symptomatic } \\
\text { treatment }\end{array}$ & Euthyroidism \\
\hline & Phase 2 (thyrc & c phase) & & $5 \%$ diffuse uptake & & CBZ for 6 months & \\
\hline \multirow[t]{2}{*}{4} & \multicolumn{3}{|c|}{ Phase 1 (thyroiditis phase) } & Negligible uptake & $\begin{array}{l}\text { Triphasic thyroiditis, } \\
\text { Graves' disease }\end{array}$ & $\begin{array}{l}\text { Symptomatic } \\
\text { treatment }\end{array}$ & Euthyroidism \\
\hline & \multicolumn{3}{|c|}{ Phase 2 (thyrotoxic phase) } & $8 \%$ diffuse uptake & & CBZ for 6 months & \\
\hline 5 & $\mathrm{~F} / 49$ & $\mathrm{C}$ & 48 & $9 \%$ diffuse uptake & Graves' disease & $\begin{array}{l}\text { CBZ for } 12 \\
\text { months }\end{array}$ & Euthyroidism \\
\hline
\end{tabular}

CBZ, Carbimazole

PTU after 6 months of therapy and remained euthyroid a further 12 months after.

\section{Case 5}

A 48-year-old woman presented for ongoing management of her thyroid disease after her first course of interferon therapy. She had chronic hepatitis $\mathrm{C}$ of genotype 1 with cirrhosis. She underwent a first course of treatment with combination IFN- $\alpha$ and RBV for 48 weeks and did not achieve end of treatment response (ETR). Her thyroid surveillance throughout this had been entirely normal. Four weeks after completion the first course, she developed GD with hyperdynamic cardiovascular activity in the presence of a confirmed diffuse goitre. Her TSH was $<0.03$, fT4 was 88.7 and fT3 of $11.3 \mathrm{pmol} / \mathrm{L}$. Her anti-Tg was 80, anti-TPO was 234 and hTRAb $13.9 \mathrm{IU} / \mathrm{L}$. The thyroid pertechnetate uptake scan showed diffuse uptake at $11 \%$. Her thyroid condition came under control in the ensuing 12 weeks with carbimazole. Six weeks after completion of the first course, she commenced a second course of combination IFN therapy for an additional 48 weeks. Her thyroid condition came under control and remained normal during this period with a maintenance dose of carbimazole. Her antiviral therapy was otherwise uneventful. Carbimazole therapy was ceased after 18 months, coinciding with the time of sustained virologic response (SVR) assessment. When reviewed 24 months after Graves' diagnosis, she remained euthyroid without any medication. Figure 1 and Table 1 summarise the sequence of events in all cases.

\section{Discussion}

This is the first case series to document the prevalence, progress and natural history of GD in the setting of IFN therapy. Graves' disease per se is not an uncommon condition in the general population with a lifetime prevalence of $0.5-1.0 \%$. However, in the setting of IFN- $\alpha$ and ribavirin treatment, our series estimates the prevalence to be at about 1 per 100 treatments, consistent with peer reports of between 0.8 and $1.3 \%$ $[5,6]$. Other reports often mention patients with this condition but the diagnostic criteria for both GD and thyrotoxicosis are poorly defined or altogether lacking [7-9]. In addition, the diagnostic criteria for GD are poorly defined but may be characterized by a triad of clinical and biochemical thy- 
Table 2. Thyroid Autoantibody Profiles Before and After Thionamide Therapy in the Five Cases

\begin{tabular}{lllllll}
\hline \multirow{2}{*}{ Subject No. } & \multicolumn{2}{l}{ Anti-thyroglobulin } & \multicolumn{2}{l}{ Anti-thyroperoxidase } & \multicolumn{2}{l}{ hTRAb } \\
& Before & After & Before & After & Before & After \\
\hline 1 & 10 & 12 & 271 & 41 & 30.2 & $<2$ \\
2 & 8 & 11 & 149 & 28 & 16.6 & $<2$ \\
3 & 1597 & 89 & 1176 & 78 & 3.3 & $<2$ \\
4 & 22 & 26 & 258 & 75 & 19.3 & $<2$ \\
5 & 41 & 68 & 38 & 25 & 13.9 & 5.8 \\
\hline
\end{tabular}

The 'After' antibody levels are measured after 6 months (at the end) of therapy.

rotoxicosis, positive hTRAb titres and/or increased nuclear uptake scans.

In this small series, the development of GD was quite unpredictable and could occur at any stage. Case 1 developed during therapy and in fact was so traumatic that treatment was terminated. This was the first case of co-existing GD and toxic nodular disease in the literature. Cases $2 \& 3$ both developed GD after the planned treatment for HCV infection. The latter developed GD eight weeks after treatment and it remains contentious whether IFN was directly responsible for its development. Cases $4 \& 5$ developed GD following tri-phasic thyroiditis which occurred in association with hepatitis $\mathrm{C}$ and interferon. The Graves' phase occurred in the post treatment period in both cases. This is consistent with other reports $[10,11]$. Interestingly, the reverse is yet to be reported. A notable characteristic in this study is that the thyroid uptake is below that expected in more classic GD although the diagnosis is well supported by the hTRAb titres and the clinical course.

This condition is rare and is often missed due to lack of follow-up and inadequate frequent thyroid surveillance. Of the 5 cases, 3 occurred in conjunction with other co-existing symptoms such as that of nodular disease in case 1, and part of the tri-phasic thyroiditis in cases 4 and 5. Only 2 cases developed GD in isolation but after treatment completion. Symptoms are equally unreliable as they can be confused with those arising from interferon treatment. The occurrence of GD after treatment is unusual and may well be coincidental as it is expected the IFN effect to have waned by then. However, Savvas et al reported GD occurring 12 weeks after therapy [11]. Kee et al [12] reported 6 cases of hyperthyroidism that were consistent with GD. Four cases persisted requiring antithyroid drugs although the duration of treatment was not reported. One was given radioactive iodine I-131 after 54 months because of the persistence of symptoms. Other reports only involved IFN- $\alpha$ monotherapy. Doi et al [13] reported 9 cases of hyperthyroidism in which prolonged antithyroid was required, in one case up to 9 years. Wong et al [3] described 6 cases of GD occurring up to 9 months after therapy. Other manuscripts recognised this peculiar condition but did not study treatment outcomes and follow-ups [14-16].

Pathogenetically, GD occurring in this situation is IFNdriven although it must occur in genetically predisposed individuals [17]. Interferon- $\alpha$ induces high expression of IFNinducible genes and $\mathrm{MCH}-\mathrm{II}$ antigens and $\mathrm{TSH}$ receptors on thyroid gland, leading to the development of clinical GD [18]. Interferon is also thought to modulate the switching of the T-cell response to $\mathrm{T}_{\mathrm{H}} 2$ and stimulate $\mathrm{B}$ cell proliferation which increases TSI production provoking the development of GD [19]. What remains undetermined is the prolonged influence of IFN after its termination to account for the development of GD post therapy. Conversely and logically, the condition should abate or regress spontaneously upon the withdrawal of this medication. However, once occurred, GD is unlikely to remit spontaneously and treatment is invariably necessary. What can be modified however is the duration of treatment, which can be reduced to 6 months. The remission of hTRAB titre is also a useful marker and may guide the termination of therapy.

It is also observed that the condition responded well to thionamide and was relatively easy to control, especially in the absence or removal of IFN. This is contrary to patients with spontaneous GD where conventional treatment is 12 18 months in total [20]. With the exception of case 5, where treatment with IFN was reintroduced and thionamide was required to continue, the other cases responded rapidly and necessitated withdrawal of anti-thyroid medication at 6 months due to hypothyroidism. Further regular thyroid surveillance did not reveal any relapse. This appears to be consistent with the withdrawal of the immunomodulating effect following IFN termination. Thionamides, especially Propylthiouracil, should be used cautiously in this population due to its potential adverse hepatic effects on an already compromised or- 
gan. This series makes the observation that IFN-related GD responds well to thionamide therapy. The condition appears to parallel IFN therapy and abates with its termination. The removal of the immunostimulation effect is also evident by the normalization of hTRAb titres where the relevant cases all achieved and maintained remission (Table 2).

The major drawback from this report is clearly the small number of subjects, primarily due to the low prevalence of the condition. The second is the short duration of follow-up. Ideally, a longer follow-up period should apply although this is made more challenging by the itinerant tendencies of the subjects. These are observational cases and further reports with larger numbers are required to consolidate the understanding of the pathogenesis. It is important to that the medium to longer term natural history of this thyroid entity is understood to prevent unnecessary treatment such as radioactive iodine therapy which will render the patients permanently hypothyroid $[12,16]$.

In summary, and notwithstanding the small number of subjects, GD in this setting occurs in two forms: in isolation or adjoining thyroiditis. The condition appears to remit more rapidly than its spontaneous counterpart, especially with the cessation of IFN therapy as reflected by the resolution of hTRAb. Treatment for 6 months followed by 12 month follow-up appears satisfactory, especially with the resolution of hTRAb titre. Thionamide should be continued if IFN is extended. This study is important so that unnecessary radioactive iodine is not deployed earlier in the course as to render the patients permanently hypothyroid.

\section{Major points of difference between IFN-induced and de novo Graves' disease}

1) Interferon induced Graves' disease incidence approximates $1 \%$ in the setting of IFN treatment. 2) Interferon induced Graves' disease can occur at anytime; during, after or in conjunction with thyroiditides. 3) Human TRAb is invariably elevated and parallels IFN treatment duration. 4) Uptake studies can be normal, but not absent contrary to the thyroiditides. 5) Consideration should be given to 6 months of thionamide therapy as opposed to the standard $12-18$ months in de novo GD therapy.

\section{Competing Interests}

There are no competing interests pertaining to any of the authors, either financial or non-financial.

\section{Authors' Contributions}

HAT conceived the study, participated in its design, assisted with data collection and coordinated and helped to draft the manuscript. GEMR participated in the design, discussion and drafting of the manuscript. Both authors read and approved the final report.

\section{Acknowledgement}

We would like to sincerely thank Geoffrey M Kellerman for his review and constructive comments of this manuscript.

\section{References}

1. Cooper DS. Hyperthyroidism. Lancet 2003;362(9382):459-468.

2. Weetman AP. Graves' disease. N Engl J Med 2000;343(17):1236-1248.

3. Wong V, Fu AX, George J, Cheung NW. Thyrotoxicosis induced by alpha-interferon therapy in chronic viral hepatitis. Clin Endocrinol (Oxf) 2002;56(6):793-798.

4. Tran HA. The swinging thyroid in hepatitis $\mathrm{C}$ infection and interferon therapy. QJM 2010;103(3):187-191.

5. Costelloe SJ, Wassef N, Schulz J, Vaghijiani T, Morris $\mathrm{C}$, Whiting S, Thomas M, et al. Thyroid dysfunction in a UK hepatitis $\mathrm{C}$ population treated with interferon-alpha and ribavirin combination therapy. Clin Endocrinol (Oxf) 2010;73(2):249-256.

6. Gelu-Simeon M, Burlaud A, Young J, Pelletier G, Buffet C. Evolution and predictive factors of thyroid disorder due to interferon alpha in the treatment of hepatitis $\mathrm{C}$. World J Gastroenterol 2009;15(3):328-333.

7. Masood N, Ghori R, Memon A, Memon S, Memon KI, Memon I, Jaffri M, et al. Frequency of thyroid disorders during interferon and ribavirin therapy in chronic hepatitis C infection. J Coll Physicians Surg Pak 2008;18(6):347-351.

8. Jamil KM, Leedman PJ, Kontorinis N, Tarquinio L, Nazareth S, McInerney M, Connelly C, et al. Interferoninduced thyroid dysfunction in chronic hepatitis C. J Gastroenterol Hepatol 2009;24(6):1017-1023.

9. Kryczka W, Brojer E, Kowalska A, Zarebska-Michaluk D. Thyroid gland dysfunctions during antiviral therapy of chronic hepatitis C. Med Sci Monit 2001;7 Suppl 1:221-225.

10. Bohbot NL, Young J, Orgiazzi J, Buffet C, Francois M, Bernard-Chabert B, Lukas-Croisier C, et al. Interferonalpha-induced hyperthyroidism: a three-stage evolution from silent thyroiditis towards Graves' disease. Eur J Endocrinol 2006;154(3):367-372.

11. Savvas SP, Papakostas N, Giannaris M, Malaktari S, Koskinas J, Archimandritis AJ. Interferon alpha-induced hashimoto thyroiditis followed by transient graves disease in a patient with chronic HCV infection. South Med 
J 2010;103(6):585-588.

12. Kee KM, Lee CM, Wang JH, Tung HD, Changchien CS, $\mathrm{Lu}$ SN, Wang PW. Thyroid dysfunction in patients with chronic hepatitis $\mathrm{C}$ receiving a combined therapy of interferon and ribavirin: incidence, associated factors and prognosis. J Gastroenterol Hepatol 2006;21(1 Pt 2):319326.

13. Doi F, Kakizaki S, Takagi H, Murakami M, Sohara N, Otsuka T, Abe T, et al. Long-term outcome of interferonalpha-induced autoimmune thyroid disorders in chronic hepatitis C. Liver Int 2005;25(2):242-246.

14. Lisker-Melman M, Di Bisceglie AM, Usala SJ, Weintraub B, Murray LM, Hoofnagle JH. Development of thyroid disease during therapy of chronic viral hepatitis with interferon alfa. Gastroenterology 1992;102(6):2155-2160.

15. Watanabe U, Hashimoto E, Hisamitsu T, Obata H, Hayashi N. The risk factor for development of thyroid disease during interferon-alpha therapy for chronic hepatitis C. Am J Gastroenterol 1994;89(3):399-403.
16. Ward DL, Bing-You RG. Autoimmune thyroid dysfunction induced by interferon-alpha treatment for chronic hepatitis $\mathrm{C}$ : screening and monitoring recommendations. Endocr Pract 2001;7(1):52-58.

17. Tomer Y. Hepatitis $\mathrm{C}$ and interferon induced thyroiditis. J Autoimmun 2010;34(3):J322-326.

18. Kuang M, Wang S, Wu M, Ning G, Yao Z, Li L. Expression of IFNalpha-inducible genes and modulation of HLA-DR and thyroid stimulating hormone receptors in Graves' disease. Mol Cell Endocrinol 2010;319(1-2):2329.

19. Cargnel A, Gubertini G, Magnani C, Bosis S, Colombo $\mathrm{F}$, Clerici M. Immune response in chronic hepatitis Cinfected patients undergoing interferon treatment. Hepatology 1999;30(2):584-585.

20. Abraham P, Avenell A, McGeoch SC, Clark LF, Bevan JS. Antithyroid drug regimen for treating Graves' hyperthyroidism. Cochrane Database Syst Rev 2010;(1):CD003420. 